\title{
BI-CULTURING OF GRASS PEA AND BARLEY IN THE SEMI-ARID REGIONS OF IRAN
}

\author{
Khoshnood Alizadeh*, Mahmoud Pooryousef', Agrawal Shiv Kumar \\ Dryland Agricultural Research Institute, \\ Maragheh, Iran
}

Received: 19-04-2012

Accepted: 11-09-2012

\section{ABSTRACT}

Forage production during summer is a challenge in the semi-arid dry areas. There is a short season window after the cereal harvestin the Iranian semi-arid regions that remains fallow till the next growing season. The present study was carried out to identify a suitable crop option to use this short period of two months for forage production. Three seeding rates of grass pea were studied inpure stand and as mixture with volunteer crop of barley from shattered seeds. Forage production and quality related traits were evaluated when grass pea reached flowering stage that coincided with the initial creamy stages of barley. The analysis showed that fresh biomass, and calcium and fiber contents were highly significant $(P<0.01)$. The highest fresh biomass (43 ton/ha) was obtained in the mixture of barley with grass pea at $200 \mathrm{seeds} / \mathrm{m}^{2}$. The highest fiber content $(23.5 \%)$ and relatively low ash content (12.6\%) were achieved in the mixture of barley with grass pea at $200 \mathrm{seeds} / \mathrm{m}^{2}$. It was concluded that the mixed cropping of barley with grass pea at $200 \mathrm{seeds} / \mathrm{m}^{2}$ was the best combination after barley harvesting using a few irrigations in the semi arid areas.

Key words: Forage crops, Hordeum vulgare, Lathyrus sativus.

Forage production during summer season is a challenge in the semi-arid dry areas. Forage crops become more important with increasing demand for meat and milk in the developing countries (Delgado, 2003). There are suitable opportunities to increase forage production without any decrease in cultivated areas under major cereal crops. G rass pea (Lathyrus sativus L.) and other neglected crops offer viable options for forage production. Forage crops cannot be recommended for cultivation at the expense of cereal crops which are defined as strategic crops for food security in most countries including Iran (Anonymous, 2010). Therefore, it is necessary to look for new opportunities. Cereals are dominant crops in semi-arid region and there is a short season window between the harvest of cereals in early J uly and planting of new crops in early October which normally is left as summer fallow in the semi-arid regions of Iran. There is generally no rainfall during J uly to late September in these areas (Modarres and
Da Silva, 2007). It is possible to provide a little irrigation water in some areas for growing forage crops. However, selected crops should grow fast and complete the production cycle during maximum 60 days as the normal winter crops planting starts early October in these areas.

After harvesting of cereals including wheat and barley there is a considerable amount of shattered seeds which remainin the field during summer and usually are eaten away by birds or insects (Lamei et al, 2011). The rate of shattering is generally high depending on harvesting method and machinery, however, it is believed that there is a minimum $5 \%$ shattering in barley and wheat (Lamei et al, 2011). Barley production rate is around 3000 $\mathrm{kg} / \mathrm{ha}$ under irrigated conditions in semi-arid areas and its $5 \%$ shattering ( $150 \mathrm{~kg} / \mathrm{ha}$ ) is optimum seeding rate for barley in these areas. It sounds that planting a suitable crop just after harvesting of cereals could alleviate the already shattered seeds to produce a

\footnotetext{
*Corresponding author's e-mail: khoshnod2000@ yahoo.com

${ }^{1}$ Mahabad Branch, Islamic Azad University, Mahabad, Iran

'International Center for Agricultural Research in the Dry Areas (ICARDA), Rabat, Morocco
} 
mixed cropping. Mixed cropping of cereals with forage legumes can improve both quantity (M pairwe et al, 2003) and quality of fodder over a pure cereal crop (Ghosh, 2004). Considerable variation has been reported in forage yields of improved vetches (Vicia spp.) and grass pea (Lathyrus spp.) under semi-arid conditions (Alizadeh and Shiv, 2013). Grass pea can grow successfully and complete flowering during 50-60 days which fits summer fallow, perfectly. Planting of grass pea with minimum tillage just after harvesting the cereals using a few irrigations can lead a mixture of cereals and legumes in order to enhance forage production. The objective of the present work was to evaluate pure stands along with mixtures of already shattered barley seeds with a local variety of grass pea at three seeding rates immediate after the barley harvest.

The experiment was carried out involving seven treatments in a randomized complete block design with three replications at Malekan Agricultural Research Station in the Northwest Iran in the summer season of 2010. Experimental field was prepared by chisel and $40 \mathrm{~kg} / \mathrm{ha} \mathrm{N}$ and $20 \mathrm{~kg} / \mathrm{ha} \mathrm{P}_{2} \mathrm{O}_{5}$ were applied uniformly to the soil just after the barley (cv. Makoii) harvest in the mid J uly 2010. The seven treatments comprised of 4 pure stands including pure barley (B), pure grass pea at 150 seeds $/ \mathrm{m}^{2}$ ( $\left.\mathrm{G} 150\right)$, pure grass pea at 200 seeds $/ \mathrm{m}^{2}$ (G200) and pure grass pea at 250 seeds $/ \mathrm{m}^{2}$ (G250) along with 3 mixed including $B+G 150, B+G 200$ and $B+G 250$. Plot size was $10 \mathrm{~m}^{2}$. Seeds of grass pea (cv. Naghadeh local) were planted and irrigated immediately. Pure stands of grass pea were created by eliminating of germinated barley and other weeds. Hay was harvested when grass pea initiated pod formation, which coincided with the milky stage of barley. Samples from a randomly selected $1 \mathrm{~m}^{2}$ area of each plot were cut to the ground level. Sub-samples $(0.3$ $\mathrm{kg}$ biomass from each plot) were dried at $70^{\circ} \mathrm{C}$ for $48 \mathrm{~h}$ for quality analysis.
SPSS software (SPSS, 1998) was used for statistical analyses. Treatment mean differences were separated by the Duncan's multiple range test (DMRT) at the 0.05 probability level.

The analysis of variances showed significant $(P<0.01)$ differences among treatments for fresh biomass production, and calcium and fiber contents (Table 1). The crop was harvested in midSeptember so as to have enough turn over time for land preparation for the subsequent winter crop. This guaranteed that there is no time interaction between grass pea and the major winter crops which is a limiting factor in the introduction of grass pea as suitable crop for this purpose.

Little information has been available regarding grass pea and its capacity for mixing with barley in order to forage production during summer season. The results showed its potential for producing a recognizable biomass during summer in the north-west Iran. The Northwest of Iran is clustered as semi arid region and is known with its short spring and dry summer (Anonymous, 2010). This study showed a variation for forage production potential among the different mixtures of grass pea with barley. The highest fresh biomass (45.3 ton/ ha) was obtained in the mixture of barley with grass pea at 200 seeds $/ \mathrm{m}^{2}$ (Figure 1) which is $50 \%$ more than pure barley yield (Figure 1).

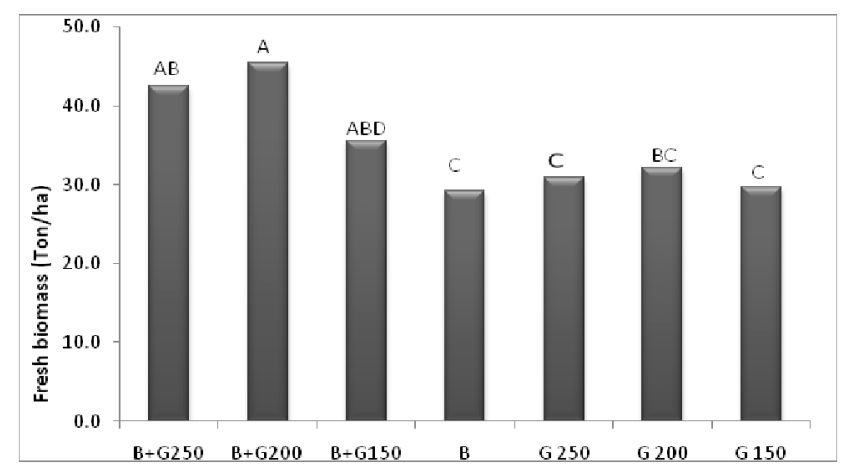

FIG. 1: Mean fresh biomass production (Ton per hectare) over pure stands and different mixtures of grass pea $(G)$ with barley (B).

TABLE 1: Analysis of variance on some studied characteristics in different mixtures of grass pea with barley

\begin{tabular}{lccccccc}
\hline SV & \multirow{2}{*}{ DF } & \multicolumn{3}{c}{ MS } & & & \\
& & Fresh biomass & Plant height & Calcium \% & Fiber \% & Ash \% \\
\hline Block & 2 & 116.37 & $23.84^{* *}$ & $0.003^{*}$ & 0.035 & 0.001 \\
Treatment & 6 & $126.67^{*}$ & $108.09^{* *}$ & $0.02^{* *}$ & $3.47^{* *}$ & $4.96^{* *}$ & \\
Error & 12 & 42.47 & 3.66 & 0.0001 & 0.064 & 0.026 & \\
\hline
\end{tabular}

** and * are significant at $1 \%$ and $5 \%$ probability level, respectively 
The highest fiber content (Figure 2) and relatively low ash content $(12.6 \%$ ) was achieved in the mixture of barley with grass pea at 200 seeds $/ \mathrm{m}^{2}$ (Figure 2). High fiber content in the bi-cultures meant low feeding value in these treatments comparing pure grass pea. However, mineral contents were higher in the bi-cultures comparing with pure stands of grass pea as reflected in the higher ash contents (Figure 2). The calcium percent in the mixture of barley with grass pea at 200 seeds $/ \mathrm{m}^{2}$ was not significantly different from pure grass pea stands (Figure 2). This means that we can produce much forage with high quality using suitable seed density of grass pea.

It was concluded that immediate by after the barley harvest, cultivation of grass pea at 200 seeds/ $\mathrm{m}^{2}$ can produce recognizable forage crop in the semiarid regions. It is a remunerative alternative for summer fallow and is especially recommended in

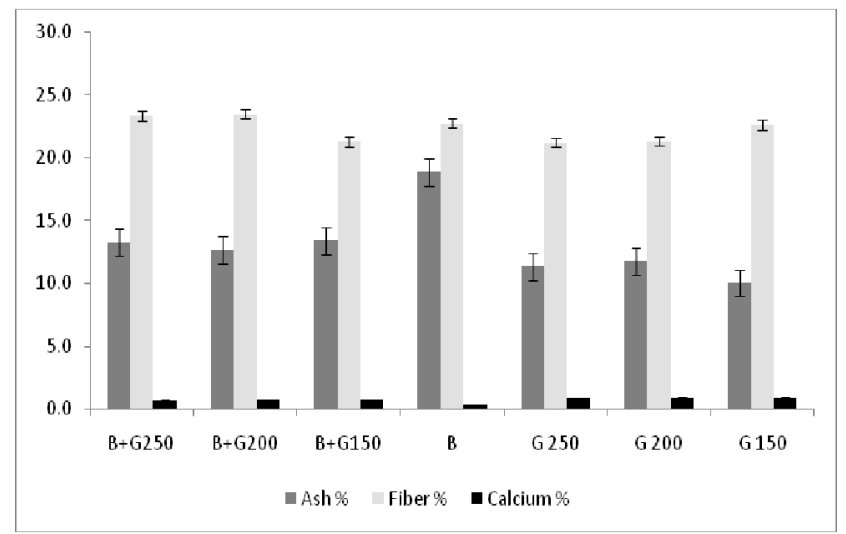

FIG. 2: Mean Ash, Fiber and Calcium percent over pure stands and different mixtures of grass pea (G) with barley (B). those regions where farmers cannot produce enough forage during summer season. Controlling of summer weeds, recycling of the cereal grains falls and enhancing the soil fertility using grass pea as a summer crop are planned for further research.

\section{REFERENCES}

Anonymous (2010). National Statistical Newsletter. Ministry of J ihad-e-Agriculture, Iran

Alizadeh K. and Shiv Kumar A. (2008). Development of vetches and grass pea as suitable crops for highlands of Iran. 11th International Conference on Dryland Development. 18-23 March 2013, Beijing, China.

Delgado C.L. (2003). Rising consumption of meat and milk in developing countries has created a new food revolution. J. Nutr.vol. 13: 3907-3910

G hosh P. K. (2004). G rowth yield competition and economics of groundnut/cereal odder intercropping systems in the semi-arid tropics of India. Field Crops Res., 88:227-237

Lamei J ., Alizadeh K., Teixeira da Silva J .A. \& Taghaddosi M.J . (2011). Vicia panonica: A suitable cover crop for winter fallow in cold regions of Iran. Plant Stress 6(1): 73-76

Modarres R., and Da Silva R.V. (2007). Rainfall trends in arid and semi-arid regions of Iran. J ournal of Arid Environments, 70:344-355

Mpairwe D.R., Sabiti E.N., Umuna N.N., Tegegne A. and Osuji P. (2003). Integration of forage legumes with cereal crops: 1: effects of supplement with graded levels of lablab hay on voluntary food intake, digestibility, milk yield and milk composition of crossbred cows fed maize-lablab Stover or oats-vetch hay. Livestock Production Science 79: 193-212.

SPSS. (1998). SPSS Base 8.0 User's Guide and SPSS A pplications Guide, SPSS, Chicago, p. 256. 